\title{
Effects of a Remedial Linguistic Program to Improve the Translation of Arabic Prepositions by Translators
}

\author{
Reem Ibrahim Rabadi \\ School of Applied Humanities and Languages \\ German Jordanian University \\ Amman, Jordan \\ Haytham Hamad Althawbih \\ School of Basic Sciences and Humanities \\ German Jordanian University \\ Amman, Jordan
}

\begin{abstract}
Prepositions initiate major problems to translators when they translate texts from Arabic into English or vice versa. This study is designed to identify the difficulties concerning prepositions, which Arab translators face when translating into English. It aims to answer two questions: First, is there an effect of a proposed remedial program to improve the translation of prepositions from English into Arabic by translators working at translation offices? Second, which of these themes (replacing a preposition with a preposition, replacing a preposition with an adverb, preposition omission, preposition addition, and preposition misplacement) of the remedial linguistic program will improve the proficiency of the translators in translating prepositions from English into Arabic? To answer these questions, 50 sentences were translated from English into Arabic by twenty translators selected randomly from the Middle East. This study sample was divided into an experimental group that executed the remedial linguistic program, and a control group that did not. The (t-test) was utilized to test the statistical significance of the differences between the two groups. Results showed statistically significant differences in mean scores between the experimental group and control group to the reference of the experimental group. It was indicated that the remedial linguistic program achieved its purpose to enhance the correct usage of prepositions by translators when they translate texts from English into Arabic.

Keywords: Arabic Prepositions, preposition omission, preposition misplacement, preposition addition, translation

Cite as: Rabadi, R. I., \& Althawbih, H. H. (2018). Effects of a Remedial Linguistic Program to Improve the Translation of Arabic Prepositions by Translators. Arab World English Journal for Translation \& Literary Studies, 2 (2). DOI: http://dx.doi.org/10.24093/awejtls/vol2no2.3
\end{abstract}

